\title{
UM ESTUDO SOBRE SENTIDOS DA MEDIDA SOCIOEDUCATIVA DE INTERNAÇÃO NA VIDA DE ADOLESCENTES INSTITUCIONALIZADOS
}

\author{
UN ESTUDIO SOBRE SENTIDOS DE LA MEDIDA SOCIOEDUCATIVA \\ DE INTERNACIÓN EN LA VIDA DE ADOLESCENTES \\ INSTITUCIONALIZADOS
}
A RESEARCH ABOUT MEANINGS OF SOCIO-EDUCATIONAL INTERNMENT MEASURE IN THE LIFE OF INSTITUTIONALIZED ADOLESCENTS

\author{
Thaíssa Fernanda Kratochwill Oliveira ${ }^{1}$ e Lilian Miranda ${ }^{1}$ \\ ${ }^{1}$ Universidade Federal Rural do Rio de Janeiro, Seropédica/RJ, Brasil
}

\begin{abstract}
RESUMO: O presente artigo é o desdobramento de uma pesquisa mais ampla que investigou a função da medida socioeducativa de internação na vida de adolescentes que cumpriam tal medida em uma instituição do Rio de Janeiro e discute os sentidos atribuídos por estes sujeitos à determinação judicial e à experiência do cumprimento da medida. Adotando a perspectiva hermenêutica em pesquisa qualitativa e o método clínico-qualitativo, foram realizadas entrevistas abertas com oito adolescentes e utilizada a observação participante. O estudo de suas histórias de vida permitiu a observação de aspectos de suas construções subjetivas sobre sua relação com a criminalidade e com o cumprimento da medida socioeducativa. Em relação ao sistema socioeducativo, os relatos revelaram aspectos da rotina no dia-a-dia e da assistência prestada aos adolescentes na instituição, bem como suas consequências em seu processo socioeducativo, sendo possível apontar possíveis estratégias de aperfeiçoamento do potencial socioeducativo das unidades do sistema. PALAVRAS-CHAVE: Adolescentes; Crime; Psicanálise.
\end{abstract}

RESUMEN: Desdoblamiento de un estudio más amplio que investigó la función de la medida socioeducativa de internación en la vida de adolescentes que cumplían tal medida en una institución de Río de Janeiro, este artículo discute los sentidos atribuidos por estos sujetos a la determinación judicial y a la experiencia del cumplimiento de la medida. Adoptando la perspectiva hermenéutica en investigación cualitativa y el método clínico-cualitativo, se realizaron entrevistas abiertas con ocho adolescentes, además de observación participante. El estudio de sus historias de vida permitió la observación de aspectos de sus construcciones subjetivas sobre su relación con la criminalidad y con el cumplimiento de la medida socioeducativa. En relación con el sistema socioeducativo, los relatos revelaron aspectos de la rutina y de la asistencia prestada a los adolescentes en la institución, así como sus consecuencias en su proceso socioeducativo, siendo posible indicar posibles estrategias de perfeccionamiento del potencial socioeducativo de las unidades del sistema.

PALABRAS CLAVE: Adolescentes; Crimen; Psicoanálisis.

ABSTRACT : This article is a consequence of a study that investigated the role of the socio-educational measure of internment in the life of adolescents who fulfilled such measure in an institution of Rio de Janeiro and discusses the meanings attributed to the judicial determination and the experience of the fulfillment of the measure. Adopting the hermeneutic perspective in qualitative research and the clinical-qualitative method, open interviews were conducted with eight adolescents and the participant observation was used. The study of their life histories allowed the observation of aspects of their subjective constructions about their relation with crime and the fulfillment of the measure. About the socio-educational system, the reports revealed aspects of the routine and of the assistance provided to the adolescents in the institution, as well as their consequences in their socio-educational process, allowing to point out possible strategies for improving the socio-educational potential of the units of the system.

KEYWORDS: Adolescents; Crime; Psychoanalysis. 


\section{Introdução e objetivos}

Aderindo à tendência internacional de adoção da Doutrina da Proteção Integral das Nações Unidas, em 1990 o Brasil viveu uma transformação paradigmática no que diz respeito às políticas públicas de atenção a crianças e adolescentes, criando o Estatuto da Criança e do Adolescente (ECA). Passa-se a buscar a garantia de direitos da infância e a criticar políticas que preconizavam intervenções pontuais, predominantemente norteadas por objetivos corretivos e punitivos. Crianças e adolescentes passam então a ser considerados como sendo sujeitos de direitos (Vicentim, 2006).

Em relação aos adolescentes envolvidos em alguma prática análoga à criminosa, com o ECA fica estabelecida a condução ao cumprimento de uma medida socioeducativa, cujos moldes variam em função das características da ação praticada pelos adolescentes, bem como dos meios que estes possuem para cumpri-las. Dividem-se em: I - orientação e apoio sociofamiliar; II - apoio socioeducativo em meio aberto; III - colocação familiar; IV - acolhimento institucional; V - liberdade assistida; VI - semiliberdade; VII - internação (Lei $\left.n^{\circ} 8069 / 1990\right)$.

Diversos autores concordam com os benefícios das modificações propostas pelo ECA. Entre estas, destaca-se a substituição da concepção menorista - presente no antigo Código de Menores de 1979, na qual crianças e adolescentes pobres eram considerados um perigo social - pela doutrina da proteção integral, que prevê que as crianças e adolescentes, sem discriminação de qualquer tipo, sejam consideradas pela legislação específica como sujeitos de direitos, que devem ser resguardados em qualquer hipótese (Scisleski et al., 2014). Baseado nesta doutrina, o ECA estabelece, ainda, no caso de adolescentes acusados de cometer atos infracionais, o direito ao devido processo legal, o direito à defesa e o caráter socioeducativo das medidas que venham a ser aplicadas (Malvasi, 2011). No entanto, cabe-nos perguntar, entre outras coisas, quais têm sido os efeitos destas mudanças sobre a constituição subjetiva dos adolescentes? Como estes as vivenciam e que sentidos lhes são atribuídos a partir da experiência de assistência que estes adolescentes recebem?

Entre os estudos em psicologia que tratam do sistema socioeducativo, destacam-se pesquisas de caracterização dos sujeitos internados, indicando a constituição, em sua maioria, de uma população de baixa renda e escolaridade, com histórico de conflitos e/ ou violência no meio familiar ou de convivência dos adolescentes (Monteiro et al., 2011; Morais \& Malfitano, 2014; Souza \& Costa, 2013). Observam-se ainda publicações sobre relatos de experiências de atendimento psicológico no sistema socioeducativo, apontando a baixa articulação com a rede externa de serviços e instituições de uma forma geral, e reforçando o potencial transformador de parcerias com as universidades (Gallo, 2008), ou de projetos envolvendo atividades esportivas (Silvestre, Oliveira, Piccione, \& Lemos, 2008). Por outro lado, algumas pesquisas mostram que socioeducandos em sofrimento psíquico são encaminhados a comunidades terapêuticas religiosas ou que, quando encaminhados para o Sistema Único de Saúde (SUS), tendem a ser tratados quase que exclusivamente com medicamentos (Morais \& Malfitano, 2014; Vilarins, 2014).

Além dessas pesquisas, as investigações sobre os sentidos das medidas para adolescentes e seus familiares observam alguma forma de delegação da responsabilização pelos sujeitos ao Estado, no sentido de esperar que este corrija algo que 'estava dando errado', seja na perspectiva dos adolescentes ou dos pais (Coutinho et al., 2011; Dias, Arpini, \& Simon, 2011; Feijó \& Assis, 2004; Gallo \& Willians, 2008; Gomes \& Conceição, 2014; Jimenez \& Frasseto, 2015; Malvasi \& Adorno, 2014; Souza \& Costa, 2012, 2013; Teixeira, 2014). 
Neste artigo, partimos do entendimento de que a institucionalização não é um caminho natural e sim uma condição, um arranjo criado a partir dos desdobramentos sociopolíticos da vida social. Sendo assim, interessa-nos conhecer os sentidos que os adolescentes - considerados aqui como protagonistas de sua própria história - elaboram e expressam, seja sobre sua participação em atos criminosos, seja sobre a experiência do cumprimento de uma medida socioeducativa. Para tanto, discutimos parte dos resultados de um estudo maior, cujo objetivo foi conhecer a função da medida socioeducativa de internação na vida de adolescentes que cumpriam tal medida em uma instituição da cidade do Rio de Janeiro/RJ.

\section{Método}

Realizou-se um estudo qualitativo, tendo por base epistemológica a hermenêutica gadameriana (Denzin \& Lincoln, 2006). Para a construção do material empírico, utilizou-se o Método Clínico Qualitativo (Turato, 2010), tendo como ferramentas a observação participante e as entrevistas semiestruturadas, cujos principais temas foram: composição familiar; condição socioeconômica; experiência de escolarização; relações familiares e sociais mais amplas; relacionamentos afetivos; relação com atividades ilícitas; e recordações pessoais suscitadas pelas entrevistas.

A pesquisa foi realizada em uma unidade de internação destinada ao cumprimento de medidas socioeducativas por adolescentes de 16 a 21 anos de idade, oriundos da Capital ou demais regiões do estado do Rio de Janeiro. Estima-se que à época do estudo, a unidade abrigava entre 400 e 450 internos, que lá permaneciam em tempo integral. Os adolescentes eram atendidos por uma equipe interdisciplinar, composta por psicólogos, assistentes sociais e terapeutas ocupacionais, além de obterem uma consulta com um defensor público uma vez por semana.

As fases preliminares da pesquisa envolveram visitas à instituição e reuniões com a direção, técnicos e agentes de segurança para apresentação do projeto de pesquisa e indicação dos entrevistados. Para tanto, utilizou-se como critérios para a indicação dos sujeitos da pesquisa, além do desejo dos sujeitos de participar, a existência de históricos de internação de tempos variados entre eles, diferentes idades e inserção em facções criminosas diversas. A adoção destes critérios baseou-se na estratégia de garantir alguma pluralidade no perfil dos sujeitos entrevistados, no que diz respeito à possível influência das diferentes idades e das formas peculiares de funcionamento de cada facção. Já sobre o tempo variado de internação, buscou-se investigar influências que a experiência de permanência na instituição poderia ter na subjetividade dos adolescentes.

Foram entrevistados oito adolescentes, com os quais foram realizados de um a quatro encontros com duração média de uma hora e meia, conforme sua disponibilidade e as necessidades da pesquisa. O trabalho de campo foi desenvolvido entre janeiro e maio de 2017 , com a presença da pesquisadora na instituição de duas a três vezes por semana. Para tanto, utilizou-se também um diário de campo, no qual eram anotadas impressões da pesquisadora sobre sua relação com os entrevistados e acontecimentos presenciados no cotidiano institucional. 
Para organização e discussão dos resultados da pesquisa, fizemos sucessivas leituras das transcrições de todas as entrevistas e das anotações do diário de campo. Nesse processo, estávamos atentas a conteúdos que se repetiam, mas sobretudo àquilo que se mostrava relevante na construção da história dos entrevistados. Tal relevância era identificada a partir da ênfase que os adolescentes davam a algumas partes de seus relatos ou à relação destas com os sentidos atribuídos a certos acontecimentos e experiências da vida.

Desse modo, o material empírico foi organizado em três eixos temáticos: "no movimento: a relação do sujeito com o crime cometido", "os sentidos e funções da medida socioeducativa" e "os projetos de futuro". A discussão desses eixos foi feita através do diálogo com a literatura e com o referencial teórico que norteou o trabalho.

A pesquisa foi aprovada pelo Comitê de Ética da Universidade sob processo $\mathrm{n}^{\circ}$ 23083.000326/2017-16. A direção da Escola de Gestão Socioeducativa, responsável por todas as unidades socioeducativas do estado, bem como a juíza de execução de medidas socioeducativas, aprovaram a realização da pesquisa. Além da anuência dos órgãos citados, como responsáveis legais pelos adolescentes durante o período de internação, os sujeitos que aceitaram participar da pesquisa assinaram um Termo de Consentimento Livre e Esclarecido, atestando sua concordância de participação.

O referencial teórico utilizado diz respeito à psicanálise freudiana, com destaque ao papel das figuras principais de cuidado na estruturação psíquica e à noção de sujeito. Apoiando-nos em Freud (1924/2011), enfatizamos a ideia de que nem toda a vida psíquica corresponde à consciência, sendo os sujeitos marcados pela ambivalência, uma vez que estruturados por desejos e processos psíquicos que frequentemente lhe escapam ao controle consciente. A este respeito, Elia (1997) argumenta que o sujeito da psicanálise é sempre o sujeito do inconsciente, o que significa dizer que ele nunca aparece e não pode aparecer como tal. Só temos acesso a ele através de manifestações às quais chamamos "formações do inconsciente": os sonhos, sintomas, lapsos, chistes e atos falhos.

Dando ênfase à importância da vida afetiva infantil, Freud (1933/2010, p. 233) destaca 'a complicada relação emocional com os pais, o chamado 'complexo de Édipo", considerado pelo autor como o núcleo das tramas afetivas que envolvem todo caso de neurose. Considera-se, assim, que o processo simbólico que funda a constituição de todo sujeito, o evento da castração simbólica vivido no período edipiano, é possível na medida em que a função paterna interdita o desejo da mãe com o filho. Neste processo, estão em jogo as relações primordiais da criança que, segundo Freud (1933/2010, p. 278), 'são ambivalentes em alto grau; junto ao amor intenso há uma forte inclinação agressiva, e quanto mais apaixonadamente a criança ama seu objeto, mais sensível torna-se às decepções e frustrações da parte dele'. A ambivalência que permeia as primeiras relações objetais da criança, no caso específico com o pai - enquanto figura exemplo da função paterna -, ocasiona a ocorrência simultânea: (a) da frustração gerada pela interdição entre a mãe e a criança, e (b) percepção de que a interdição é exercida pela função paterna como atitude de cuidado, de caráter inevitável, tendo em vista a necessidade de introdução da criança na cultura, na vida em sociedade. Ao final desta operação, e mesmo durante a mesma, vemos que a criança compreende a figura paterna como responsável pela transmissão da Lei simbólica, da interdição do desejo, mas também como aquele que lhe fornece a passagem para o direito da convivência social. 
É importante ressaltar que ao fazer referência à figura paterna, partimos do pressuposto de que esta possui caráter simbólico, podendo ser exercida por diversos atores ou instâncias da sociedade. Mesmo diante das transformações percebidas no campo social e seus impactos nos processos de configuração familiar, (como, por exemplo, a alteração do modelo de família nuclear e heteronormativa), é possível observar as funções simbólicas sendo exercidas por quaisquer que sejam as figuras que compõem as diversas famílias. Outro aspecto importante é que não necessariamente pessoas é que exercem tais funções: um bom exemplo desta realidade diz respeito ao próprio Estado, que muitas vezes acaba sendo o responsável por realizar as funções de cuidado, orientação ou mesmo da interdição dos sujeitos, por meio de diversas formas de atuação e controle, como os abrigos, escolas, conselhos tutelares, juizados, polícia e instituições diversas.

Considerando que as manifestações inconscientes, bem como as possibilidades de elaboração consciente dos sujeitos se manifestam na linguagem, na pesquisa aqui apresentada nós convidamos os adolescentes a falar sobre sua história de vida, sua relação com o crime e com as leis.

\section{Resultados e discussão}

\section{Apresentação dos Sujeitos de pesquisa}

Os oito entrevistados eram adolescentes entre dezesseis e dezenove anos. Obedecendo a questões éticas, os nomes aqui citados, a saber: Lucas, Diogo, Tiago, Caio, Kaique, Saulo, Sérgio e Olavo, são fictícios. Antes da internação, a maioria morava com pelo menos um dos pais ou com a avó, e dois moravam sozinhos, em casas cedidas por traficantes de drogas. Apenas um se diferenciava bastante dos demais a esse respeito, afirmando ser hip- pie e estar há algum tempo viajando sem moradia fixa. À exceção deste, todos os demais moravam na cidade do Rio de Janeiro ou na região metropolitana, em locais dominados por alguma facção criminosa ou por milícias.

De modo geral, os adolescentes remetiam-se aos números de matrícula para se identificarem, raramente pronunciando seus nomes. Notou-se também o uso do termo "menor" ao referirem-se a si mesmos e aos colegas. Abandonado em 1990, a partir da criação do ECA, tal termo remonta à concepção adotada em antigas doutrinas, como o Código Mello Mattos e o Código de Menores (Assis, 2009; Paiva, 2012), que o utilizavam em referência a crianças e adolescentes considerados abandonados ou delinquentes. Nota-se ainda que, na maior parte do tempo, apesar de estarem cumprindo uma medida socioeducativa de internação, os adolescentes identificavam a instituição na qual estavam como "cadeia" e referiam-se a si mesmos como "presos", razão pela qual esta nomenclatura é também mantida no presente artigo.

A adoção dos números de matrícula atribuídos pela instituição como forma de identificar a si mesmos - em detrimento de seus nomes - parece demonstrar nos adolescentes um processo de identificação com o discurso da instituição. Além disto, ao repetir a maneira como são tratados na internação, evidenciam o que parece ser um aspecto do processo de institucionalização denominado por Goffmann (2005) como "mortificação do eu”, no qual os sujeitos vão, progressivamente, substituindo aspectos relativos à sua identidade própria por outros normatizados pela instituição: 
O novato chega ao estabelecimento com uma concepção de si mesmo que se tornou possível por algumas disposições sociais estáveis no seu mundo doméstico. Ao entrar [na instituição], é imediatamente despido do apoio dado por tais disposições. O seu eu é sistematicamente, embora muitas vezes não intencionalmente, mortificado... A barreira que as instituições totais colocam entre o internado e o mundo externo assinala a primeira mutilação do eu. (Goffman, 2005, p. 24. Parêntese nosso)

O processo identificado por Goffman (2005) diz respeito ao contexto das instituições totais, cuja característica principal é o isolamento do indivíduo do mundo externo. Sendo assim, há evidências de que a unidade de cumprimento da medida de internação esteja funcionando com características de uma instituição total.

Em geral, os adolescentes demonstraram bastante interesse em participar das entrevistas pois, além destas atuarem como uma quebra na rotina do enclausuramento, representavam espaços de escuta e acolhimento. Alguns, inclusive, informavam que colegas seus também tinham interesse em participar.

\section{"No movimento": a relação do sujeito com o crime cometido}

Alguns adolescentes puderam contar diversas cenas sobre a prática dos atos infracionais, perseguições, confrontos e a apreensão policial. Relataram também aspectos sobre o processo pelo qual respondiam, comentando o que concordavam ou discordavam acerca do que se encontra declarado no mesmo, além de sua avaliação acerca da medida que cumpriam, no sentido de a considerarem ou não justa. Abaixo, apresentamos, resumidamente, seus principais relatos sobre os motivos de sua internação e modos através dos quais foram apreendidos. Discutimos ainda questões específicas que, em alguns casos, relacionavam-se à prática dos atos infracionais ou ao evento da apreensão.

Sérgio saiu de casa após ter apanhado do pai por ter sido expulso da escola. Ele responde por acusação enquadrada em analogia ao Art. 157 do Código Penal, que refere-se a roubo mediante grave ameaça ou violência à pessoa. Sérgio discorda dos termos de seu processo, afirmando que, embora estivesse participando do roubo, não portava faca e não roubou nada efetivamente. Descreve que quando foi apreendido pelos policiais, estes puxaram suas mãos para trás, levaram-no para a delegacia e disseram: "vou te matar se eu te pegar na rua de novo". Em seguida, foi levado para o Centro de Triagem e Recepção (CTR), onde os adolescentes apreendidos passam por recepção e acolhimento, antes da primeira audiência. Após participar da audiência, foi encaminhado para a unidade de internação na qual deve cumprir sua medida.

Kaique, em sua segunda passagem pelo sistema sob acusação de roubo, descreve o passo a passo do roubo de carga que praticara com seus colegas, mas admite que, apesar de todo o planejamento, algo deu errado:

Porque a gente pegou o primeiro carro do correio, umas dez e pouca da manhã, aí tiramos tudo e liberamos o correio. Quando a gente foi pegar o outro, o outro correio, já tinha passado pelos polícia. Aí eles vieram pegar a gente e nós fomos correndo, correndo, correndo, aí a gente bateu entre o ônibus e o carro. Aí estourou o pneu, quebrou o carro todo e a gente foi preso ali. 
Diogo, filho de pais separados desde bebê, considera ter recebido assistência do pai até seus dez anos, a partir de quando considera que este "não queria muito fazer parte da minha vida não”. Envolveu-se com o tráfico quando ainda morava com sua mãe, padrasto e irmã, depois de já ter abandonado a escola e tentado investir em um trabalho como moto táxi. Justifica sua escolha porque o pai e a mãe não se dispuseram a comprar-lhe uma moto própria, acusando-o de não ter responsabilidade para pagar as prestações. Afirma que frente a tal recusa, "me revoltei e entrei pro tráfico de drogas".

Outro adolescente que falou sobre sua relação com o crime foi Caio, que desde os treze anos "roubava... pra comprar roupa de marca, curtir festa e shopping com a família". Explica que já envolveu-se na venda de drogas, mas por pouco tempo, e relata estar "preso" por furto de joias e dinheiro de um turista. Na ocasião, um policial disfarçado atirou nele e no amigo, que morreu ali mesmo, enquanto Caio corria e se escondia, até ser encontrado e "preso".

Os atos infracionais representavam uma tentativa de subversão de uma ordem na qual ele passava de excluído, impotente, a portador de um passe de acesso (dinheiro) ao que antes estava diante de seus olhos, mas que não tinha meios de obter. Ao praticar roubos, parece encontrar meios de lidar com as limitações e impotências diante de situações de perda ou falta. Em seu relato, diz que "deu um tempo" de roubar, a pedido de seu pai, o qual, tempos depois, não resistiu a um infarto e morreu. Ao relatar este episódio, Caio afirma que a partir de então passou a roubar ainda mais.

$\mathrm{O}$ adolescente, que atingiu a maioridade durante o período da pesquisa, contou ter pensado que seu filho "poderia ficar nessa de roubar se visse o pai roubando, cometendo um ato errado", o que não deve mais ocorrer, porque ele decidira parar com estes atos, de modo que o filho aprenderá "o que é certo". Momentos depois, o adolescente relata que viu seu pai traficando. Este hoje é falecido, mas já foi dono de uma "boca", nome que se atribui a um ponto de venda de drogas. Frente à minha questão sobre possíveis influências disto sobre sua vida e sobre o ato de roubar, ele afirma que roubou porque quis mesmo, afinal "ninguém rouba por causa dos outros: se os outros te chamarem pra roubar e você não quiser ir, você não vai”.

A mudança no discurso de Caio sugere uma tentativa de desvencilhar o pai e o passado familiar de alguma influência, que teria se dado por via da identificação, em sua entrada no crime. No entanto, no momento em que se vê como pai e preocupa-se com o modo como seus atos podem influenciar seu filho, parece reconhecer a importância da figura paterna na constituição subjetiva da criança, tal como discutimos a partir de Freud (1933/2010) acerca do protagonismo desta figura no processo da socialização infantil. A tentativa de abster o próprio pai de alguma responsabilidade em seu envolvimento com os roubos pode indicar ainda que, apesar de saber, de alguma forma, da influência deste passado em sua vida, Caio foi capaz de formular uma responsabilização própria diante das escolhas e do caminho que seguiu até então, a partir de suas vivências no romance familiar. Portanto, a relação de Caio com o crime passa por sua relação com seu filho e com seu próprio pai. O ato criminoso ocupa, assim, papel central em suas elaborações acerca do papel da figura paterna na transmissão das normas da cultura à próxima geração.

A temática das repetições entre as gerações da família apareceu em outros relatos, como no de Tiago, que saiu de casa e começou seu trabalho no tráfico aos doze anos, acreditando que, com isso, aliviaria o trabalho da mãe, "porque ela tinha onze filhos". Procurou o "movimento" - como é conhecido pelos moradores de uma comunidade o grupo de 
funcionários de uma boca - por iniciativa própria. Relata que após algum tempo na função de vapor, ou seja, daquele que vende a droga diretamente aos usuários, ganhou um fuzil.

Esta não é sua primeira passagem pelo sistema, mas é a primeira internação. Sua preocupação em prestar assistência à mãe se repete com sua esposa, que recebe auxílio financeiro da facção à qual Tiago pertence, enquanto ele encontra-se "preso". Pensando em sua trajetória no tráfico, conta que quando criança não via o pai. Foi apenas na adolescência que pôde conversar com ele, que já estava preso por ser o dono de uma "boca", o que fez com que este contato - iniciado pelo pai - se desse por telefone. Ao contar sobre tais conversas, diz que seu pai lamentou não ter lhe dado muita atenção, pois seu trabalho no tráfico o impedia. Em entrevista anterior, Tiago havia me relatado esta mesma queixa: que o trabalho no tráfico traz restrições ao seu próprio papel de pai.

Assim como na história de Caio, a repetição pelo filho de aspectos da trajetória do pai se fez presente. Diferente de Caio, no entanto, a relação de Tiago com seu trabalho na "boca" sugere que a identificação com as escolhas do pai em relação ao crime não lhe causam tanto incômodo. Além de afirmar que, assim como ocorreu entre seu pai e ele quando era pequeno, hoje seu trabalho no tráfico o impossibilita de "dar atenção" a seu filho, o adolescente cita outra justificativa do pai que parece trazer um sentido do qual ambos compartilham: "eu estou levando a mesma vida que eu estou vendo", evidenciando novamente a identificação com o pai.

Saulo, por sua vez, considera sua apreensão, realizada sem apoio de prova material, injusta. Passando pelo Rio de Janeiro durante uma das viagens que fazia, foi "preso" sob acusação de ter roubado dinheiro: "a polícia não me pegou com nada... não pegou com dinheiro, não pegou eu com faca. Que eles falou que eu tinha roubado de faca”.

Saulo, contudo, não é o único a queixar-se da abordagem policial, pois outros adolescentes denunciaram apreensões sem provas materiais do ato infracional, baseadas em violência e ameaças. Apenas um dos adolescentes não fez esse tipo de denúncia, tendo este relatado ser filho e irmão de policiais e ter o desejo de também seguir a carreira militar.

Como vimos em todas as entrevistas, as referências a familiares foram frequentes: pais ou parentes envolvidos com o crime, profissão policial no histórico familiar, preocupação com o que os atos infracionais cometidos ou suas consequências poderiam gerar como consequência na vida dos filhos. Esses relatos assemelham-se ao material encontrado no estudo de Souza e Costa (2013), que observou, na descrição familiar feita pelos adolescentes, históricos de violência familiar ou envolvimento com o crime por parte de familiares próximos ou distantes. Além disto, assim como os autores, identificamos o histórico de repetições relacionadas a práticas de violência de figuras mais velhas da família, especificamente no que diz respeito ao envolvimento com o tráfico de drogas.

\section{Os sentidos e funções da medida socioeducativa de internação}

A investigação acerca dos sentidos atribuídos pelos adolescentes ao cumprimento da medida socioeducativa revelou duas perspectivas distintas: a primeira diz respeito aos significados para os sujeitos da prática de um crime e sua consequente apreensão, e a segunda aos significados da experiência de cumprimento da medida, que envolve a privação de liberdade. 
Lucas narrou diversos trechos muito confusos sobre seu processo sem, no entanto, apresentar irritação por não compreender determinadas atitudes de autoridades na condução do mesmo. Ressente-se apenas do fato de a juíza não tê-lo deixado falar durante sua audiência e diz que, apesar de ter acesso à defensoria pública e advogado particular, já está há muito tempo preso e "não sabe quando vai sair dali".

Retomo aqui a questão relativa à adesão ao discurso institucional por parte dos adolescentes. Mesmo questionando a postura da juíza, que não lhe "deu a palavra”, Lucas acaba por submeter-se passivamente à decisão dela de manutenção da internação, sem maiores questionamentos sobre a arbitrariedade da conduta desta autoridade. O que chama a atenção é o fato de a indignação por não ser ouvido não ser suficiente para que ele formasse uma visão crítica sobre o julgamento feito pela juíza, que culmina nas sucessivas manutenções da medida de internação. Diante desse quadro, percebemos que o seu direito de ser ouvido durante seu processo, que lhe é garantido pelo ECA (Lei nº 8069/1990) é percebido por ele não como uma garantia legal que deve ser exigida, mas como uma espécie de "conduta desejável" a ser adotada pela autoridade judicial, algo que depende da vontade da juíza, e não uma obrigação inerente ao seu cargo.

Por um lado, a postura passiva adotada pelo adolescente diante dos imperativos da autoridade pode ser reflexo de uma trajetória de vida marcada pela omissão do adulto, quando não pela insuficiência sistemática da atuação do próprio Estado diante do imperativo de garantia de seus direitos. Nesta perspectiva, é como se o adolescente se submeter a uma posição de passividade e vulnerabilidade diante das decisões dos adultos ou responsáveis por ele, fosse algo natural e inerente à sua posição de criança ou adolescente. Por outro lado, a mesma postura passiva pode demonstrar a percepção, em algum nível, de sua inserção na dinâmica de seletividade com que, historicamente, o sistema penal tem atuado no Brasil (Alves, 2019; Batista, 2014; Zaccone, 2016; Zaffaroni 1940/2016), uma vez que, mesmo cumprindo uma medida socioeducativa, Lucas refere-se a si mesmo como "preso". Trechos discursivos como este, no qual questiona as decisões da juíza, associados a outros, nos quais demonstra discordância com o modo como foi tratado desde o evento de sua apreensão - questionando os modos de produção de provas pelos policiais, entre outros aspectos - evidenciam sim uma capacidade crítica por parte do adolescente. Tal crítica, porém, é acompanhada dos demais fatores que percebe à sua volta, ou seja, um contexto social altamente excludente, no qual um jovem negro e morador de comunidade como ele, constitui - como ele mesmo relata - um alvo frequente de abordagem, incriminação ou diversos tipos de violação de direitos. Nesse caso, a violação de seu direito de ser ouvido seria apenas mais uma das séries de violações a que Lucas já foi submetido ao longo de sua trajetória. Sem enxergar alternativas ou sentir-se capaz de subverter este processo, o adolescente se conformaria, então, a acatar as ordens da autoridade, ainda que discordasse dos critérios adotados por ela. Tais perspectivas não são excludentes, podendo complementar-se na tentativa de compreensão das elaborações subjetivas do adolescente.

Outros adolescentes lamentaram-se sobre questões parecidas, como Caio que relatou que: "a tia da saúde mental [psicóloga que realiza algum trabalho de escuta na instituição] não tá me chamando direito”, deixando claro que tinha algo a dizer. O observado aqui assemelha-se à realidade encontrada por Monteiro et al. (2011), cujos adolescentes entrevistados revelaram não serem atendidos com frequência pelos profissionais. Outra semelhança em relação ao observado pelos autores diz respeito à percepção dos adolescentes de que alguns funcionários da unidade desacreditam de sua recuperação e agem com preconceito, questão que será discutida mais adiante. 
Lucas relata ainda ter feito um acordo com sua mãe, propondo-se a parar de roubar e voltar à escola, além de frequentar um curso de Jovem Aprendiz, no qual ela havia lhe matriculado. Estava disposto a "ser um novo homem", mas, antes de começar, foi apreendido em casa pelos policiais.

Sua internação parece ter tido o poder tanto de impedir que realizasse a pretendida mudança de vida, quanto de proporcionar novas oportunidades para que ela ocorra. Ao mesmo tempo em que, por estar preso, não pode frequentar a escola ou o curso em que a mãe o havia matriculado, acredita que os cursos que fez durante a internação lhe deram meios de seguir trabalhando em profissões não ligadas ao crime, possibilidade que parecia não despertar seu interesse ou aposta antes de ser "preso".

Diogo, por sua vez, antes de receber a medida de internação, não sabia que menores de idade podiam ser "presos". Seu relato sobre o período de internação comporta bastante sofrimento, dúvidas e angústia pois, assim como Lucas, apesar de sua família ter contratado um advogado, seus sucessivos retornos de audiências com manutenção de medida de internação o deixavam cada vez mais desesperançoso quanto à sua liberação da instituição. Ele toma medicação para ajudar a dormir e diz que, assim, "a cadeia passa mais rápido".

Durante o cumprimento da medida, Diogo atingiu a maioridade, fato que, de acordo com sua própria lógica, não lhe permite mais esperar coisas de seus pais, como quando era criança ou adolescente, obrigando-o a procurar um emprego. Mudanças ocorreram também no modo como pensa em resolver suas questões dali em diante. Ao relatar um problema pessoal, Diogo explicou quais eram as medidas a serem tomadas para resolvê-lo, de acordo com o código de conduta da facção à qual pertencia. No entanto, ponderava, ressaltando: "se eu tô querendo deixar essa vida [facção, tráfico], não adianta nada eu continuar agindo nas regras de lá”.

Em alguma medida, a experiência do cumprimento da medida levou Diogo a repensar sobre determinados eventos, sendo capaz de elaborar uma lógica própria de resolução de suas demandas e conflitos, desta vez sem a mediação de sua mãe, seu pai ou dos chefes e parceiros no tráfico. Alberti (2009), ao discutir os processos pelos quais o sujeito adolescente empreende a separação dos próprios pais, afirma que, para que possa superar o discurso parental, é necessário o adolescente assumir-se enquanto objeto diferenciado, separado de tais figuras. É só separando-se do outro parental que o adolescente torna-se sujeito. Na história de Diogo, a medida parece ter tido um papel importante neste processo, proporcionado ao adolescente uma ressignificação que contribuiu para sua reafirmação enquanto sujeito.

Outro aspecto de seu relato, que foi comum no de outros entrevistados, diz respeito ao fato de que, entre os sentidos atribuídos à internação coexiste também o de "livramento", afinal, poderia ter morrido, assim como ocorreu com seu colega em sua apreensão, mas ao invés disto acabou sendo "preso". Tiago, religioso, me apresenta vários exemplos do que atribui ser a providência divina que, não apenas no dia de sua apreensão, como em vários outros, o livrou da morte ao trocar tiros com policiais.

O próximo entrevistado, Kaique, está em sua segunda passagem pelo sistema, ambas por roubo. De poucas palavras, descreve detalhes sobre os mesmos, mas quase nada sobre suas possíveis motivações e expectativas ao praticá-los. Apesar de ter relatado dificuldades em frequentar a escola, a vivência da internação parece ter lhe proporcionado a passagem por uma rotina que exigia disciplina, o que foi aproveitado para estudar, pois deseja prestar concurso para a Polícia quando sair. Em relação a isto, agora tem o apoio de seu pai, que prometeu ajudá-lo assim que ele voltar para casa. 
Outro adolescente, Caio, é marcado pela vivência da morte de muitos ao seu redor. Além do pai, relata ter visto diversos colegas e pessoas mortas na vizinhança, em meio a conflitos armados. Essas memórias lhe causam muito sofrimento e, em consequência disto, há tempos faz uso de medicação para dormir. Caio é um dos exemplos que se assemelham ao observado por Vilarins (2014), quando escreveu que as medidas socioeducativas com restrição de liberdade têm atuado como potencializadoras de sofrimento psíquico. Além de fazer uso de medicação para dormir, a dificuldade no acesso a consultas regulares com um psiquiatra faz com que o recurso da medicação, que parece ser a principal aposta em seu caso, seja, ainda assim, escasso. Tal observação constitui mais um indicativo da necessidade de investir em espaços de escuta dos adolescentes, ampliando as estratégias de prevenção e acompanhamento de seu sofrimento psíquico. Ponderamos, entretanto, que tais estratégias, por sua vez, só poderão ser elaboradas mediante a ampliação desta discussão aos espaços de formação profissional. Estes precisam incluir reflexões sobre as questões psicossociais de jovens de diferentes classes sociais, atos infracionais e legislação da infância e adolescência, bem como as características e efeitos da institucionalização em serviços que incluem reclusão ou limitação da circulação.

Os relatos dos adolescentes corroboram ainda o proposto por Silvestre et al., (2008) que, ao realizarem uma intervenção que combinava atividades esportivas com espaços de fala e negociação, observaram que os adolescentes puderam atribuir outro sentido ao acompanhamento que recebiam, tornando-se progressivamente protagonistas de suas ações e reafirmando a busca para tornarem-se sujeitos.

Os relatos de Tiago, que saiu de casa para contribuir com as condições da mãe em sustentar onze filhos, e o de Caio, que roubava para ter acesso a roupas de marca e passeios no shopping com a família, parecem evidenciar dinâmicas semelhantes às observadas por Dias et al. (2011). Os autores concluíram que a condição socioeconômica das famílias exercia forte influência nos papéis e nas atividades desempenhadas por seus membros, ou que cada vez mais a mãe tem ocupado o papel de chefe de família, acumulando responsabilidades de suprimento econômico, social e afetivo dos filhos, o que constitui mais uma evidência do reflexo das transformações sociais nas composições familiares, sobretudo nas famílias monoparentais.

No que diz respeito ao sentido atribuído à imputação da medida de internação, destacamos o seguinte trecho que ilustra as elaborações de Caio:

A juíza tem razão. Cada um tem seu trabalho: o trabalho dela é de mandar nós embora ou dar manutenção pra nós. Tem duas opções: nós tá errado de ter cometido esse erro, de roubar, e ela tá certa de ter apreendido nós pra nós ficar pensando.

Para ele, então, o que se espera que os adolescentes façam ao cumprir a medida é "ficar pensando", o que transformaria seu comportamento criminoso. No entanto, a experiência da internação, marcada pela percepção da violência e humilhação com que foi tratado pelos agentes de segurança, causa-lhe muita revolta, trazendo o desejo de vingança e afirmação de poder, ou seja, promove em seus pensamentos planos de cometer novos crimes.

Retomamos, a esse respeito, nossa aposta na oferta de espaços de escuta aos adolescentes durante a internação e consideramos, sobretudo, a importância do psicólogo, profissional capacitado para lidar com questões (inter)subjetivas e para auxiliar os adolescentes 
a romperem com o ciclo de violência no qual se encontram inseridos. Acrescentamos, ainda, que a violência envolve, além de atores externos, os próprios agentes de segurança e outros profissionais que lidam cotidianamente com os adolescentes no sistema socioeducativo. Diante desta realidade, é importante ponderar a necessidade de uma intervenção no âmbito institucional, com a oferta de dispositivos coletivos de acolhimento, escuta e análise também para os profissionais.

Outro caso que ilustra alguns sentidos encontrados pelos adolescentes para a medida socioeducativa é o de Sérgio. Apreendido em flagrante, morava com a avó desde pequeno. Sua mãe faleceu quando ele tinha dez anos de idade, morte desencadeada pelo vício em drogas, e seu pai estava preso. Assim ele define a própria vida: "Minha vida antes era só no mundo das drogas, só queria saber de roubar”. Este tipo de explicação, que centra a experiência de vida nos atos infracionais, foi algo recorrente nas respostas dos adolescentes. A observação da repetição do histórico familiar pontuada por Souza e Costa (2013) novamente aparece aqui, desta vez relacionada ao uso de drogas, na história de Sérgio e, anteriormente, de sua mãe.

Ao falar sobre sua apreensão, conta que nenhum familiar foi vê-lo na delegacia. Sobre a experiência do cumprimento da medida, diz que é "tranquilo" e não expressa nenhum plano de continuar ou deixar o crime.

Saulo, por sua vez, evidencia a cada trecho de seu relato - considerando a abordagem policial violenta, a prisão injusta e a vivência da medida como algo pobre de recursos e possibilidades - que a medida de internação não possui qualquer sentido para ele.

Olavo, cumprindo internação há quase onze meses, não consegue entrar em detalhes de como foi parar ali. Diz ter feito algo errado e estar "no tráfico de drogas e associação" referindo-se aos processos pelos quais responde. Ele me diz: "Não vou mentir. Minha vida era muito melhor do que aqui dentro... não tinha necessidade de vir parar aqui, mas eu agi descabeçado". Quando questionado sobre o que a internação mudou em sua vida, diz: "A forma de se expressar, o caráter também. A pessoa tem o caráter de aprovar sua própria palavra: sim é sim, não é não... isso muda bastante”. Afirma que a psicóloga "tirava” ele uma vez por semana "para conversar" (na sala da psicóloga).

Assim como ocorreu com Diogo, através de experiências vividas no cumprimento da medida, Olavo parece ter experimentado uma mudança no sentido de tornar-se capaz de afirmar suas opiniões e escolhas enquanto sujeito, mas, no seu caso, o trabalho da psicóloga parece ter tido um importante impacto. Ele atribui aos atendimentos a transformação que percebe em si e deseja continuar o tratamento depois que sair da instituição. A nosso ver, Olavo viveu uma nova forma de relação com a psicóloga, identificando nesta um olhar que apostava no seu futuro.

Neri \& Campos, (2008) afirmam que, em 2006, o índice de reincidência de internação no Degase era de 44\%. Embora não haja divulgação atualizada desse índice, considerando que metade dos entrevistados em nosso estudo não estavam em sua primeira passagem pelo sistema, é possível ponderar que o sistema socioeducativo tem apresentado dificuldades em alcançar o efeito a que se propõe. Muitos fatores podem ajudar a compreender esta realidade. A partir do observado no presente trabalho, aposta-se que um deles diz respeito à relação dos adolescentes com os profissionais que os atendem durante o cumprimento das medidas. 
Analisando os relatos dos adolescentes que descreviam o tratamento recebido, notou-se enorme diferença no modo como percebem ser tratados pelos diferentes profissionais. Por mais que o atendimento psicológico tenha sido considerado insuficiente, alguns dos adolescentes que afirmaram ser atendidos por psicólogos apresentaram em seu discurso algum processo de elaboração sobre suas histórias de vida, estabelecendo outras relações com as pessoas que consideram importantes, os eventos marcantes vividos e com seus desejos para o futuro.

Por outro lado, o tratamento dispensado pelos policiais, nos eventos de apreensão e, sobretudo pelos agentes de segurança socioeducativa no dia-a-dia do cumprimento da medida foi vivido com muito sofrimento. Os sentidos desta experiência referem-se à violência e desrespeito, gerando nos adolescentes sentimentos de desesperança e ódio, o que prejudicava a formulação de projetos de futuro que não envolvessem a violência e o desejo de vingança.

A partir do observado, o trabalho desses psicólogos parece ser capaz de promover o protagonismo do sujeito sobre suas próprias escolhas. Já o dos professores, de fazer com que os adolescentes pensassem sobre seu futuro profissional, buscando meios para alcançar outras modalidades de trabalho, inexploradas anteriormente. $\mathrm{O}$ que os adolescentes parecem ter identificado na relação com estes profissionais foi o olhar da aposta. Ao desenvolver um trabalho comprometido com a transformação da realidade dos adolescentes, que implica na aposta no potencial socioeducativo do próprio sistema, os psicólogos e professores dirigem aos adolescentes um olhar que lhes permite também apostar em si mesmos.

\section{"Ter uma mente": o ato infrator e os projetos de futuro}

Além dos desejos que possivelmente já faziam parte de seus planos antes da internação, houve elementos incorporados durante o cumprimento da medida, afetando diretamente os planos imaginados por eles, tanto de forma positiva, acrescentando possibilidades, como negativa.

Os planos de futuro frequentemente passaram pela ponderação sobre como seria se o adolescente continuasse praticando atos infracionais, numa espécie de naturalização desta conduta como parte de suas vidas. A possibilidade de ser preso e ir para uma cadeia exerceu bastante influência na decisão pelo afastamento dos atos criminosos, como no caso de Diogo, que "agradece" por ter sido apreendido enquanto é "de menor", e ter conhecido a experiência de ter ficado privado de liberdade logo cedo. Explica que se sua apreensão tivesse ocorrido quando fosse adulto, seria pior, porque imporia o cumprimento de uma pena num presídio. Na mesma linha, Caio acredita que a juíza quis lhe ajudar quando não lhe "soltou" em sua primeira audiência: fez isto para que ele não cometesse outro ato infracional, pois se ele praticasse algum crime agora que ele atingiu a maioridade, teria que cumprir pena em uma cadeia. Então ela o deixou ali pra "pensar, refletir", ponderar que agora tem um filho, e então "ficar tranquilo" (que significa não voltar a praticar atos infracionais).

Entre os projetos que elaboraram, estiveram o trabalho com vendas, abrindo o próprio negócio. Experiências vividas ali, como o curso de empreendedorismo realizado durante a internação, foram citadas como sendo importantes para a elaboração destes planos. Também haviam planos de voltar à escola, desta vez adotando uma postura diferente. 
Havia o objetivo de demonstrar, na escola, as mudanças pelas quais o adolescente acredita ter passado, exemplificadas como: não ser mais "o garoto que fazia pirraça, que fazia gracinha”, não ser mais "o mesmo de antes", "ser um novo homem”.

Por outro lado, considerando alguns problemas vividos durante a internação, os adolescentes também cogitam retomar algumas práticas criminosas, sem ponderar a possibilidade de serem apreendidos novamente e sem pontuar estratégias que os deixariam menos vulneráveis. Nesse sentido, Caio que planeja "ficar tranquilão quando sair... estudar, trabalhar e tentar conseguir uma escolinha de futebol”, ao me contar sobre o tratamento que recebeu desde que foi preso, diz:

Esses cara [agentes de segurança socioeducativa] ficam dando tapa na nossa cara, xingando nossa mãe, batendo em nós, xingando nós de filha da puta, acabando com nossa visita, olhando pra mãe dos outros, tu acha que eles vão passar da idade que eles é, pô? Vai não, filho. Se eu saísse e metesse a mão na boca [fosse na boca de fumo], ia pegar um por um aqui na frente... ia esperar aqui no portão, filho. Vai sofrer o que nós tá sofrendo aqui dentro também.

Houve ainda o caso de Tiago, que afirmou que permanecerá no trabalho do tráfico quando sair da internação. Apesar de seu relato comportar algum incômodo relacionado com a contradição entre o tráfico e suas crenças evangélicas, em nenhum momento cogitou seu desligamento da facção.

Nenhum dos entrevistados relatou acreditar que o fato de ter sido "preso" ofereceria obstáculos ou estigmatização, prejudicando seus planos de futuro, embora Lucas tenha mencionado o medo de ser morto por policiais após a saída em liberdade, por vingança em relação ao crime do qual fora acusado.

Entre as dificuldades que poderiam atrapalhar seus planos, um dos adolescentes afirmou que "mudar de vida não é difícil", destacando que "se a pessoa quiser sair desse caminho ela sai". Outros consideraram a realidade de precariedade socioeconômica como um fator crucial, que pode atrapalhar ou mesmo impedir a saída do crime para o trabalho formal, na medida em que as oportunidades de trabalho não são garantidas para todos.

A partir dos relatos, vimos que a internação tem oferecido meios para que os adolescentes vislumbrem possibilidades de trabalho e reavaliem alguns comportamentos. No entanto, as experiências de violência sofridas durante o cumprimento da medida os incitam a retomar práticas criminosas. Em relação a estas, além da revolta frente a maus tratos exercidos por policiais e agentes de segurança, coloca-se como causa a miserabilidade social, além dos vínculos com as facções criminosas e do poder a elas atribuído.

\section{Considerações finais}

De modo geral, os adolescentes entendem a medida socioeducativa como estratégia de punição frente a um ato do qual são acusados de modo justo ou injusto. Não aparecem reflexões significativas sobre a vulnerabilidade e a violência inerentes ao contexto social que os envolve, e suas possíveis relações com o envolvimento em atos infracionais. Ainda que tenha sido citada a possibilidade não conseguir emprego mesmo querendo "mudar de vida", tal consideração não foi suficiente para que os adolescentes discorressem sobre 
a influência do contexto social em suas condutas. Pelo contrário, é notável a presença de marcante responsabilização individual por seus atos, o que indica uma identificação com o discurso jurídico (proferido por juízas que os atendem) e, de modo mais amplo, parece refletir o discurso que permeia a sociedade neoliberal em que vivemos.

É importante atentar para o perigo da adoção desse tipo de discurso individualizante, na medida em que ele comporta a possibilidade de altos níveis de frustração por parte dos jovens que passam a atribuir a si mesmos toda a culpa pelas dificuldades de sua trajetória de vida. Ao desconsiderar o papel de atores sociais, tais como seus responsáveis, o Estado, a escola, as políticas públicas, os fatores socioeconômicos e políticos que envolvem a vida de qualquer população, tem-se um reducionismo perverso, cujas consequências negativas são incalculáveis, sobretudo se considerarmos os adolescentes enquanto sujeitos em desenvolvimento. Neste sentido, iniciativas que atentem para a responsabilização dos profissionais quanto ao poder e as consequências de seu discurso na formação destes adolescentes também fazem-se imprescindíveis.

Para alguns adolescentes, a aplicação da medida parece ter servido como meio de transformação e busca por autonomia em relação aos pais. Outros puderam repensar na relação das gerações da família com o crime, desejando abandoná-lo, em alguns casos. Em um dos casos, a escolha pelo trabalho no tráfico foi reafirmada e, em outro, não foi encontrado nenhum sentido. É importante observar, contudo, que de maneira geral, os sentidos elaborados pelos adolescentes sobre a internação relacionaram-se fortemente com o modo como percebiam ser tratados pelos diferentes profissionais da instituição. Maus tratos sofridos por policiais e agentes de segurança, para muitos, servem como uma espécie de incentivo ou justificativa para a continuidade de práticas violentas e criminosas, alimentando um ciclo de violência que parece ter sido naturalizado. Acompanhando esta tendência, a adoção do uso de números atribuídos pela instituição como forma de identificar a si mesmos parece demonstrar um processo de identificação dos adolescentes com o discurso da instituição. Além disto, ao repetir a maneira como são tratados, os sujeitos evidenciam o que parece ser uma consequência do processo de institucionalização, no qual os sujeitos vão, progressivamente, substituindo aspectos relativos à sua identidade por outros normatizados pela instituição.

Aqueles adolescentes que contavam com algum espaço de escuta e aposta em seus futuros, parecem ter construído projetos de vida que não envolviam práticas criminosas ou consideraram de modo mais amplo suas consequências. O modo como aproveitaram as entrevistas de pesquisa também apontou a existência do desejo de narrar suas histórias e, contando com a escuta de alguém, (re)construir sentidos para as experiências da internação e para aquelas que as antecederam. Acreditamos, assim, que a pesquisa teve algum efeito de intervenção, permitindo que os adolescentes se sentissem reconhecidos e avançassem um pouco mais em seus processos de reconhecimento como sujeitos.

Concluímos enfatizando que um sistema que se propõe a gerar mudanças nos adolescentes que cometem atos infracionais deve levar em consideração que só se pode mudar algo na própria vida na medida em que se possa pensar e refletir sobre ela. Considera-se fundamental, portanto, a oferta de um espaço de escuta aos adolescentes, bem como intervenções que levem em conta a violência presente na dinâmica relacional entre os demais agentes envolvidos no trabalho com este público no sistema socioeducativo. 


\section{Referências}

Alberti, S. (2009). Esse sujeito adolescente. Rio de Janeiro: Rios Ambiciosos/Contra Capa. Alves, D. (2019). Perversidade e racismo na justiça penal. Revista Ponte (online). Recuperado de https://ponte.org/artigo-perversidade-e-racismo-na-justica-penal/

Assis, S. G. et al. (Org.). (2009). Teoria e prática dos conselhos tutelares e conselhos dos direitos da criança e do adolescente. Rio de Janeiro: Fiocruz. Recuperado de http://prattein.com.br/home/ images/stories/230813/direitos_crianca_adolescente/curso_conselho_tutelar.pdf

Batista, V. M. (2003). O medo na cidade do Rio de Janeiro: dois tempos de uma história. Rio de Janeiro: Revan.

Coutinho, M. P. L., Estevam, I. D., Araújo, L. F., \& Araújo, L. S. (2011). Prática de privação de liberdade em adolescentes: um enfoque psicossociológico. Psicologia em Estudo, 16(1), 101109.

Dias, A. C. G., Arpini, D. M., \& Simon, B. R. (2011). Um olhar sobre a família de jovens que cumprem medidas socioeducativas. Psicologia E̋ Sociedade; 23(3), 526-535.

Denzin, N. K. \& Lincoln, Y. S. (2006). O planejamento da pesquisa qualitativa: teorias e abordagens. Porto Alegre: Artmed.

Elia, L. (2007). O conceito de sujeito (2a. ed.) Rio de Janeiro: Jorge Zahar.

Feijó, M. C. \& Assis, S. G. (2004) O contexto de exclusão social e de vulnerabilidades de jovens infratores e de suas famílias. Estudos de Psicologia, 9(1), 157-166.

Freud, S. (2010). O mal-estar na civilização e outros textos (1930-1936) (P. C. Souza, Trad., Vol. 18). São Paulo: Companhia das Letras. (Original publicado em 1933)

Freud, S. (2011). O eu e o id, "autobiografia" e outros textos (1923-1925) (P. C. Souza, Trad., Vol. 16). São Paulo: Companhia das Letras (Original publicado em 1924)

Gallo, A. E. (2008) Atuação do psicólogo com adolescentes em conflito com a lei: a experiência do Canadá. Psicologia em Estudo, 13(2), 27-334.

Gallo, A. E. \& Williams, L. C. A. (2008) A escola como fator de proteção à conduta infracional de adolescentes. Cadernos de Pesquisa, 38(133), 41-59.

Goffman, E. (2005). Manicômios, prisões e conventos (7a ed.). São Paulo: Perspectiva.

Gomes, C. C. \& Conceição, M. I. G. (2014). Sentidos da trajetória de vida para adolescentes em medida de liberdade assistida. Psicologia em Estudo, 19(1), 47-58.

Jimenez, L. \& Frasseto, F. A. (2015). Face da morte: a lei em conflito com o adolescente. Psicologia E Sociedade, 27(2), 404-414.

Lei 1n. 8.069, de 13 de julho de 1990. (1990). Dispõe sobre o Estatuto da Criança e do Adolescente e dá outras providências. Brasília, DF: Presidência da República.

Malvasi, P. A. (2011) Entre a frieza, o cálculo e a "vida loka”:violência e sofrimento no trajeto de um adolescente em cumprimento de medida socioeducativa. Saúde e Sociedade, 20(1), 156170 .

Malvasi, P. A. \& Adorno, R. C. F. (2014). A vulnerabilidade e a mente: conflitos simbólicos entre o diagnóstico institucional e a perspectiva de jovens em cumprimento de medida socioeducativa. Saúde e Sociedade, 23(1), 30-41.

Monteiro, E. M. L. M., Almeida, A. J., Waldemar Brandão, W., Brady, C. L., Freitas, R. B. N., \& Aquino, J. M. (2011). Desafios e perspectivas na reeducação e ressocialização de adolescentes em regime de semiliberdade: subsídios para Enfermagem. Revista de Enfermagem Referência, III (3), 37-46. Recuperado de http://www.scielo.mec.pt/scielo.php?script=sci_ abstract\&pid=S0874-028320 $11000100004 \& \operatorname{lng}=$ pt\&nrm=iso

Morais, A. C. \& Malfitano, A. P. S. (2014). Medidas socioeducativas em São Paulo: os serviços e os técnicos. Psicologia \&̊ Sociedade, 26(3), 613-621. 
Neri, N. E. \& Campos, L. A. (2008). "Crime, juventude e punição - a internação de jovens em conflito com a lei no Estado do Rio de Janeiro". In XXVI Reunião Brasileira de Antropologia (p.12). Porto Seguro, BA: Associação Brasileira de Antropologia. Recuperado de http:// www.abant.org.br/conteudo/ANAIS/CD_Virtual_26_RBA/foruns_de_pesquisa/trabalhos/ FP\%2009/natasha\%20elbas_luiz\%20augusto.pdf

Paiva, L. J. (2012). A construção histórica da adolescência e a sua abordagem jurídica no Brasil. Revista Eletrônica Jurídica, 1(1), 1-12. Recuperado de http://docplayer.com.br/30327883-A-construcao-historica-da-adolescencia-e-a-sua-abordagem-juridica-no-brasil.html

Scisleski, A. C. G., Galeano, G. B., Caldeira, J. L., \& Santos, S. N. (2014). Medida Socioeducativa de Internação: dos Corpos Dóceis às Vidas Nuas. Psicologia: Ciência e Profissão, 34(3), 660-675.

Silvestre, F., Oliveira, F. H. S., Piccione, M. A., \& Lemos, R. F. (2008). Futebol Libertário: Compromisso Social na Medida. Psicologia: Ciência e Profissão, 28(3), 558-573

Souza, L. A. \& Costa, L. F. (2012). O significado de medidas socioeducativas para adolescentes privados de liberdade. Acta Colombiana de Psicología 15(2), 87-97.

Souza, L. A. \& Costa, L. F. (2013). A significação das medidas socioeducativas para as famílias de adolescentes privados de liberdade. Psico-USF, 18(2), 277-288.

Teixeira, L. C. (2014). O sujeito adolescente e a intervenção psicanalítica: notas a partir de um caso clínico. Rev. Latinoam. Psicopat. Fund., 17 (3-Suppl.), 797-804.

Turato, E. R. (2010). Tratado da metodologia da pesquisa clínico-qualitativa: construção teórico-epistemológica, discussão comparada e aplicação nas áreas da saúde e humanas. Petrópolis, RJ: Vozes. Vicentim, M. C. G. (2006). Infância e adolescência: uma clínica necessariamente ampliada. Revista de Terapia Ocupacional da Universidade de São Paulo, $17(1)$, 10-17.

Vilarins, N. P. G. (2014). Adolescentes com transtorno mental em cumprimento de medida socioeducativa de internação. Ciência E̊ Saúde Coletiva, 19(3), 891-898.

Zaccone, O. D. F. (2016). Indignos de vida: a forma jurídica da política de extermínio de inimigos na cidade do Rio de Janeiro. Rio de Janeiro: Revan.

Zaffaroni, E. R. (2016). O inimigo no direito penal (S. Lamarão, trad., $3^{\mathrm{a}}$ ed.). Rio de Janeiro: Revan. (Original publicado em 1940) 


\section{THAÍSSA FERNANDA KRATOCHWILL OLIVEIRA}

\section{https://orcid.org/0000-0002-3004-4368}

É psicóloga, mestre em Psicologia, Universidade Federal Rural do Rio de Janeiro.

Endereço: BR 465, Km 07, s/n Zona Rural, Seropédica - RJ. CEP: 23890-000.

E-mail: thaissa.fko@gmail.com

\section{LILIAN MIRANDA}

\section{http://orcid.org/OOOO-0002-8238-8111}

É psicóloga, doutora em Saúde Coletiva. Pesquisadora da ENSP/FIOCRUZ.

E-mail: limiranda78@hotmail.com

\begin{tabular}{ll}
\hline Histórico & $\begin{array}{l}\text { Submissão em: 29/11/2017 } \\
\text { Revisão em: 14/03/2019 } \\
\text { Aceite em: 09/06/2019 }\end{array}$ \\
& Concepção: TFKO; LM. \\
& Coleta de dados: TFKO; LM. \\
& Análise de dados: TFKO; LM. \\
Elaboração do manuscrito: TFKO. & Crítico revisões de conteúdo intelectual importante: \\
TFKO; LM. & Final aprovação do manuscrito: TFKO; LM. \\
& $\begin{array}{l}\text { Pesquisa financiada pelo Programa de Demanda Social } \\
\text { da Coordenação de Aperfeiçoamento de Pessoal de Nível }\end{array}$ \\
& Superior (CAPES.) \\
Financiamento & Não se aplica \\
Consentimento de uso de & O estudo foi aprovado pela Universidade Federal Rural \\
imagem & do Rio de Janeiro (UFRRJ) e pelo Departamento Geral \\
de Ações Socieducativas (DEGASE).
\end{tabular}

